University of Louisville

ThinkIR: The University of Louisville's Institutional Repository

$12-2014$

\title{
The effect of a controlled frequency breath holding training program on running economy among elite college swimmers.
}

Patrick Sims 1988-

University of Louisville

Follow this and additional works at: https://ir.library.louisville.edu/etd

Part of the Exercise Physiology Commons

\section{Recommended Citation}

Sims, Patrick 1988-, "The effect of a controlled frequency breath holding training program on running economy among elite college swimmers." (2014). Electronic Theses and Dissertations. Paper 1764. https://doi.org/10.18297/etd/1764

This Master's Thesis is brought to you for free and open access by ThinkIR: The University of Louisville's Institutional Repository. It has been accepted for inclusion in Electronic Theses and Dissertations by an authorized administrator of ThinkIR: The University of Louisville's Institutional Repository. This title appears here courtesy of the author, who has retained all other copyrights. For more information, please contact thinkir@louisville.edu. 
THE EFFECT OF A CONTROLLED FREQUENCY BREATH HOLDING TRAINING PROGRAM ON RUNNING ECONOMY AMONG ELITE COLLEGE SWIMMERS

\author{
By \\ Patrick Sims \\ B.S., University of Kentucky, 2011 \\ A Thesis \\ Submitted to the Faculty of the \\ College of Education and Human Development \\ in Partial Fulfillment of the Requirements \\ for the Degree of \\ Master of Science \\ Department of Exercise Physiology \\ University of Louisville \\ Louisville, Kentucky
}

December 2014 

THE EFFECT OF A CONTROLLED FREQUENCY BREATH HOLDING TRAINING PROGRAM ON RUNNING ECONOMY AMONG ELITE COLLEGE SWIMMERS

\author{
By \\ Patrick Sims \\ B.S., University of Kentucky, 2011 \\ A Thesis Approved on \\ November 21,2014 \\ Date Approved \\ by the following Thesis Committee: \\ Thesis Director \\ Dr. Gerald S. Zavorsky \\ Dr. T. Brock Symons
}

Dr. Craig A. Harms 


\title{
DEDICATION
}

This thesis is dedicated to my parents

\author{
Mr. Jeffrey Sims \\ and
}

Mrs. Heidi Sims

who have always been my greatest champions. 


\section{ACKNOWLEDGEMENTS}

I would like to express great appreciation to my thesis chair and mentor, Dr.

Gerald S. Zavorsky, for his patience and valuable insight. This body of work would not exist without his support.

I would like to thank my Thesis Committee for their dedication to reviewing and bettering the caliber of this document. I appreciate their willingness to further my educational experience through their fine acumen. Additionally, the faculty of the Exercise Physiology department at the University of Louisville has been invaluable in advising me as I have progressed. Thank you to Dr. Ann Swank, Dr. Daniela Terson de Paleville, Dr. Adrienne Bratcher, and Dr. Kathy Carter for caring deeply about my success, for providing me their advice, and for listening when I needed their ear.

My fellow thesis partners Alex Burtch and Ben Ogle deserve more than a thank you. Without their selfless contribution of time and energy to our entire project, none of us would have accomplished what we have. I wish them the best of luck in their own Thesis journey and beyond. The future is bright for them both.

Finally, my circle of colleagues, friends and family has been more patient and understanding than I deserve. Many thanks for your tolerance and compassion, your support and your love. 


\begin{abstract}
THE EFFECT OF A CONTROLLED FREQUENCY BREATH HOLDING TRAINING PROGRAM ON RUNNING ECONOMY AMONG ELITE COLLEGE SWIMMERS

Patrick Sims

December 4, 2014
\end{abstract}

Running economy (RE) is the amount of oxygen consumed while running at a submaximal intensity. Along with aerobic capacity $\left(\mathrm{VO}_{2 \max }\right), \mathrm{RE}$ is an important predictor of running performance. Little research has investigated changes in RE with restricted breathing training [i.e. controlled breath-holding (CFB)] during exercise. RE may improve $\sim 6 \%$ amongst a novice swimming cohort through CFB training, but this has not been established in elite swimmers. The purpose was to further establish that CFB training (16 sessions of $12 \times 50-\mathrm{m}$ with $\sim 15$ seconds rest between each $50-\mathrm{m}$, using only $\sim 2$ breaths per $50-\mathrm{m}$ ) can improve RE in 25 elite college swimmers. CFB training did not alter RE. The day-to-day variability in $\mathrm{RE}(\mathrm{mL} / \mathrm{kg} / \mathrm{km})$, energy cost $(\mathrm{kcal} / \mathrm{kg} / \mathrm{km})$, and $\mathrm{VO}_{2 \max }(\mathrm{L} / \mathrm{min})$ was between $2.4-3.4 \%$. There was no association between $\mathrm{RE}$ (range = 182 to $224 \mathrm{~mL} / \mathrm{kg} / \mathrm{min}$ ) and 200 yard freestyle swimming performance (range $=104$ to 129 seconds). 


\section{TABLE OF CONTENTS}

$\begin{array}{ll}\text { Dedication } & \text { iii }\end{array}$

Acknowledgements

Abstract $\quad$ V

List of Tables viii

Chapter 1. Introduction 1

1.1 Statement of the Problem 1

1.2 Purpose of the Study 5

$\begin{array}{ll}1.3 \text { Significance of the Study } & 6\end{array}$

$\begin{array}{lc}\text { 1.4 Literature Review } & 6\end{array}$

1.4.1 Running economy versus maximal oxygen consumption 6

1.4.2 Running biomechanics and running economy 8

1.4.3 Heart rate and running economy 10

1.4.4 Respiratory muscle fatigue, hypoxia, altitude, and running economy 10

1.4.5 Controlled frequency breath holding and running economy 12

1.4.6 Allometric scaling of running economy $\quad 13$

1.4.7 Operational definitions for literature review 14

1.5 Research Questions \& Hypotheses 14

$\begin{array}{ll}1.6 \text { Assumptions } & 15\end{array}$

Chapter 2. Methods 16

$\begin{array}{ll}\text { 2.1 Subject Selection } & 16\end{array}$

$\begin{array}{ll}2.2 \text { Settings } & 17\end{array}$

$\begin{array}{ll}2.3 \text { Procedures } & 17\end{array}$

2.3.1 Pre and Post-Testing 17

2.3.2 Training Intervention 19 
2.3.3 Research Design 20

2.3.4 Statistical Analysis $\quad 21$

2.3.5 Data Management and Storage 22

3. Results 24

4. Discussion 26

4.1 Discussion Overview 26

$\begin{array}{ll}4.2 \text { Normal Values for RE } & 27\end{array}$

$\begin{array}{ll}4.3 \mathrm{RE} \text { and Swimming Performance } & 29\end{array}$

4.4 Familiarization trials for RE testing $\quad 30$

4.5 Day-to-day-variability in RE $\quad 30$

4.6 Limitations 31

References $\quad 34$

Tables $\quad 42$

$\begin{array}{ll}\text { Curriculum Vitae } & 47\end{array}$ 


\section{LIST OF TABLES}

TABLE 1 Subject Characteristics $\quad 42$

TABLE 2 Experimental Design of Intervention 43

TABLE 3 Cardiopulmonary data of all subjects,

familiarization versus baseline $\quad 44$

TABLE 4 Results of selected variables between groups,

Controlled Frequency Breath Holding (intervention)

versus Stroke-Matched (control) 45

TABLE 5 Reproducibility of running economy and

cardiopulmonary variables at maximal exercise

46 


\section{CHAPTER 1}

\section{INTRODUCTION}

\subsection{Statement of the Problem}

Swimming is a popular sport in collegiate athletics. According to the 2012 United States Census, there were approximately 21,000 National Collegiate Athletic Association (NCAA) swimmers in 2009-2010. In NCAA competition, competitive swimmers compete with one of four swimming strokes, each with its own unique rhythmicity, including butterfly, breast stroke, backstroke, and front crawl, sometimes known as, "freestyle" (Gupta \& Goswami, 2001). This thesis focuses on 200 yard freestyle swimming performance in NCAA swimmers at the University of Louisville.

Freestyle swimming uniquely limits access to ventilation as dictated either by stroke choice/frequency, athlete's choice, or both, whereas terrestrial sports provide unfettered access to ventilation patterns of one's choosing. In this way, swimming training as a primary discipline may cause substantial change to one's respiratory performance (McKay, Braund, Chalmers, \& Williams, 1983). Oxygen consumption at any intensity $\left(\mathrm{VO}_{2}\right)$, (and at maximal int ${ }^{\circledR}$ ensity, $\mathrm{VO}_{2 \max }$ ) represents a culmination of musculoskeletal, cardiovascular, and respiratory function. In the elite athlete, the respiratory system may be a limiting factor to endurance performance (Bye, Farkas, \& Roussos, 1983; Lavin, Guenette, Smoliga, \& Zavorsky, 2013). Swimming is an 
interesting event to study the respiratory system since swimmers usually have very large lungs (Andrew, Becklake, Guleria, \& Bates, 1972).

Although an athlete's aerobic capacity $\left(\mathrm{VO}_{2 \max }\right)$ has traditionally been assessed via a graded exercise test to volitional exhaustion, running economy (RE) can also be measured this way. Running economy is the submaximal $\mathrm{VO}_{2}$ at any given running speed and is usually expressed in terms of milliliters of oxygen consumed per kilogram of body weight per kilometer of distance traveled $(\mathrm{mL} / \mathrm{kg} / \mathrm{km})$.

Technically, the term, "economy" is most specific to the amount of oxygen consumed at submaximal intensity, while the term, "efficiency" refers to the amount of work done per unit of speed. Since running velocity is not a direct measure of work, efficiency is technically a different index. With that said, the terms economy and efficiency are frequently used interchangeably in the existing literature on running economy (Luhtanen, Rahkila, Rusko, \& Viiasalo, 1990; Yoshida, Udo, Iwai, \& Yamaguchi, 1993) and may be used interchangeably within this document, assuming both are queries into one's oxygen consumption versus their running velocity.

The measurement of RE has been shown to be a good predictor of endurance performance when runners of the same aerobic capacity are matched (Conley \& Krahenbuhl, 1980; Conley, Krahenbuhl, Burkett, \& Millar, 1981; J. T. Daniels, 1985; Morgan, Martin, \& Krahenbuhl, 1989). Running economy is an expression of one's overall physiological efficiency, while aerobic capacity is the measurement of one's physiological "power". In other words, the lower the amount of oxygen required to run a given distance (normalized to body mass), the more physiologically efficient one is. 
Running economy could be equated to the fuel economy of a car, wherein less fuel per mile used represents a more economical vehicle. $\mathrm{VO}_{2 \max }$ on the other hand would be represented in a vehicle's horsepower; a measure of capacity to create maximal amounts of work irrespective of fuel cost. Thus, a Toyota Prius may be a very efficient car with little horsepower, while a Ford Mustang is more powerful but not efficient.

This balance of economy and capacity has led to much investigation of the intersections of $\mathrm{RE}$ and $\mathrm{VO}_{2 \max }$; the relationship is debated and appears to differ greatly based on the population and study in question. Some studies have found that there is a negative relationship between $\mathrm{RE}$ and $\mathrm{VO}_{2 \max }$, suggesting that as the amount of oxygen that is required to run a given distance decreases, $\mathrm{VO}_{2 \max }$ is increased (Morgan et al., 1995; Morgan \& Daniels, 1994; Padilla, Bourdin, Barthelemy, \& Lacour, 1992; Pate, Macera, Bailey, Bartoli, \& Powell, 1992; Tartaruga et al., 2013).Other research has found that $\mathrm{RE}$ and $\mathrm{VO}_{2 \max }$ in fact are not related (Anderson, 1996; Mooses et al., 2014; Reeves, Corbett, \& Barwood, 2014; Santos-Concejero et al., 2014), and yet others have found that as $\mathrm{RE}$ gets worse ( $\mathrm{VO}_{2}$ increases) $\mathrm{VO}_{2 \max }$ is low between the two (Mooses et al., 2014) To complicate matters, research has even found that, while related, $\mathrm{RE}$ and $\mathrm{VO}_{2 \max }$ can fail to predict running performance (Grant, Craig, Wilson, \& Aitchison, 1997). On the whole, the relationship between $\mathrm{RE}$ and $\mathrm{VO}_{2 \max }$ is complicated in research and not fully agreed upon.

A recent investigation found that RE could be improved by a particular swimming training, namely by restricting breathing during swimming training (Lavin et al., 2013). This is accomplished by inspiring air to total lung capacity (TLC) and then holding this air for several strokes before taking another breath. This technique, called controlled 
frequency breath holding (CFB) may improve swimming performance by training the respiratory muscles to become fatigue resistant. Lavin et al. demonstrated that limiting breathing frequency in swimming training resulted in faster swimming times and improved RE (Lavin et al., 2013). They postulated that there was an improved muscular oxygen utilization since $\mathrm{RE}$ was improved $\left(\mathrm{VO}_{2}\right.$ was lower) among recreational swimmers.

Lavin et al. did not investigate what the mechanism of improvement was exactly, although they suggested that the improvement in RE was a result of a change in peripheral muscle. The rate of oxygen diffusion into the mitochondria has been established as one limiting factor of $\mathrm{VO}_{2 \max }$ (di Prampero, 2003), so this is a potential site for improvement, although the mechanisms by which hypercapnia may affect oxygen diffusion at the cell is not well understood. Some research has looked at effects of hypercapnia on relationships between cerebral oxygen diffusion and the enzymes cytochrome C oxidase and nitric oxide synthase (Gjedde, 2005), but this cannot be assumed to apply likewise to skeletal muscle.

No matter the mechanism of change in Lavin's cohort, it has yet to be investigated whether the same results can be replicated among elite swimmers, who presumably already possess substantial respiratory muscle strength. Among a welltrained cohort of triathletes that increased swimming and cycling volume by $\sim 50 \%$, their $\mathrm{RE}$ or $\mathrm{VO}_{2 \max }$ were not altered compared to before the study began (Palazzetti, Margaritis, \& Guezennec, 2005). Thus, sheer volume of exercise will not suffice. Therefore, it bears investigating just what cardiopulmonary training interventions may improve oxygen consumption in swimmers. 
Running economy, being an expression of one's oxygen consumption for a given running speed, is an important factor apart from one's $\mathrm{VO}_{2 \max }$, which has been thoroughly investigated as a major indicator of aerobic potential (Barnes \& Kilding, 2014). The body of research on factors affecting RE is substantially smaller than that of $\mathrm{VO}_{2 \max }$, and stands to be developed greatly in emerging literature. Running economy should be assumed to always represent the physiological efficiency of one's movement while at submaximal intensity. The state of the literature currently shows several factors that may modestly affect RE, although only one up to this point has investigated RE among swimmers, and then with a recreationally fit subject pool. Mechanisms established as affecting RE are many, including, but not limited to: training volume and longevity (Midgley, McNaughton, \& Jones, 2007), biomechanical differences among athletes (Santos-Concejero et al., 2013), shoe design (Sobhani et al., 2014), minute ventilation $\left(\mathrm{V}_{\mathrm{E}}\right)$, altitude, hypoxia, core temperature, (Saunders, Pyne, Telford, \& Hawley, 2004a) and more. Each of these influences will be examined in-depth below as potential informants on this intervention.

\subsection{Purpose of the Study}

This study aimed to assess whether a four week intervention of controlled frequency breath holding (CFB) training can improve either $\mathrm{RE}$ or $\mathrm{VO}_{2 \max }$ among elite, collage-aged swimmers. The four week protocol was selected to accurately recreate the intervention used by Lavin et al. (2013).

Utilizing the experimental procedures of Lavin et al. (2013), this study focuses on an elite swimming cohort, which is an interesting group to study due to their enhanced 
conditioning. The potential that a lifetime of swimming has positively influenced the respiratory development of these subjects is not ignored; childhood and adolescent vigorous swimming training has previously demonstrated augmentation of total lung capacity (Andrew et al., 1972; McKay et al., 1983; Sarro, Silvatti, \& Barros, 2008; Zinman \& Gaultier, 1987) . All subjects within this cohort were competitive swimmers since adolescence.

\subsection{Significance of the Study}

Demonstrating a relationship between RE and swimming performance may show that CFB training can improve changes at the muscular level, allowing locomotor muscles to perform the same amount of work with less oxygen. If CFB training can indeed improve RE among an elite cohort of swimmers, the common crossover of swimming to multisport post-collegiate competition may bring with it important training methodology for improving terrestrial performance. Likewise, demonstration of improvement in $\mathrm{RE}$ or $\mathrm{VO}_{2 \max }$ by $\mathrm{CFB}$ training would invite further scholarly research to see if CFB training can be used exclusively terrestrially to improve RE among nonswimming athletes.

\subsection{Literature Review}

\subsubsection{Running economy versus maximal oxygen consumption}

As mentioned above, the relationship between $\mathrm{VO}_{2 \max }$ and $\mathrm{RE}$ is highly debated. Some research suggests $\mathrm{VO}_{2 \max }$ may be positively related to RE (Mooses et al., 2014). Thus, the more oxygen that is required to cover a given distance, the higher the RE. The homogenous group in question, elite Kenyan distance runners, who had worse RE than a 
European comparison group, still demonstrated superior $\mathrm{VO}_{2 \max }$ values and were extremely successful athletes despite worse $\mathrm{RE}$, suggesting that, a high $\mathrm{VO}_{2 \max }$ can more than compensate for poorer RE in terms of total athletic potential. What seems to be highly variable is the RE even among their elite cohort. Mooses et al. stated that the differences in RE among the subjects was mostly mechanically related. These findings are supported by Santos-Concejero et al. who found that a similar pool of North African runners demonstrated inferior RE to a comparable European subject pool as well as longer ground contact time in stride, but are still more athletically successful (SantosConcejero et al., 2013). In disagreement with this, Weston et al. found that African runners were $8 \%$ more economical than Caucasian 10km runners, but had a $13 \%$ lower $\mathrm{VO}_{2 \text { peak }}$ (Weston, Mbambo, \& Myburgh, 2000). Some researchers have gone so far as to speculate that neither of these factors predict running performance (Grant et al., 1997).

However, a large body of research suggests that $\mathrm{RE}$ and $\mathrm{VO}_{2 \max }$ are indeed negatively related (Morgan et al., 1995; Morgan \& Daniels, 1994; Pate et al., 1992). That is, the less oxygen that is needed to cover a given distance, the higher the subject's $\mathrm{VO}_{2 \max }$. Among those who found a negative relationship between $\mathrm{RE}$ and $\mathrm{VO}_{2 \max }$, it was asserted that RE is identical across sexes. (Padilla et al., 1992). Pate et al. demonstrated a positive association between $\mathrm{RE}$ and $\mathrm{VO}_{2 \max }$ among a heterogeneous group of recreational runners, while Morgan et al. showed this negative relationship to hold true across a breadth of running skill level from novice to elite (Morgan et al., 1995). They claimed that previous research failing to associate $\mathrm{RE}$ and $\mathrm{VO}_{2 \max }$ among elite levels is attributable to the amount of years at elite training status. They asserted that increases in training years appear to improve association of $\mathrm{RE}$ and $\mathrm{VO}_{2 \max }$. 
A disparity exists in the effects of $\mathrm{VO}_{2 \max }$ and performance between running and swimming; running performance is significantly correlated a runner's relative, but not their absolute, $\mathrm{VO}_{2 \max }$, whereas a swimmer's performance is correlated with their absolute, but not relative, $\mathrm{VO}_{2 \max }$ (Butts, Henry, \& McLean, 1991). This suggests that there is an incongruent interaction of maximal aerobic capacity in running and swimming, such that the latter is simply a matter of, "the size of the engine," while the former is contingent on body size interaction with $\mathrm{VO}_{2 \max }$.

Among swimmers, who presumably spend little to no time running, there can be assumed to be little influence of time-at-training specific to running biomechanics, which helps narrow the confounders of RE such that the results of this study might truthfully demonstrate any effects of CFB training.

\subsubsection{Running Biomechanics and Running Economy}

Several pieces of literature have substantiated a major influence of biomechanics on RE. Since this piece of research seeks to examine whether manipulation of the myriad factors surrounding pulmonary function can augment RE, it could prove a novel intervention for improving RE beyond the current state of the literature which has demonstrated mainly the influences of biomechanics.

The metabolic cost of running is significantly increased by wearing shoes versus barefoot running (Reeves et al., 2014). Additionally, the particular shoe worn changes RE (Sobhani et al., 2014). Logically, the addition of mass at the bottom of the foot increases the amount of torque required to complete each running stride and therefore would augment RE. Mooses et al. demonstrated a positive association between RE and Achilles 
tendon moment arm, as well as upper leg length (Mooses et al., 2014), which stands to support that the increase in leg mass is equitable to a worsening in RE.

To that effect, RE appears to be best in those with the smallest leg masses (Kong $\&$ de Heer, 2008) among elite runners. More widely, the effect of body mass has been shown to affect RE but not percent body fat (Pate et al., 1992). With that said, the groups will be randomized to help eliminate influences in body mass.

$\mathrm{RE}$ is not significantly correlated with the kinetic factors of contact time or step frequency, suggesting that personal biomechanical characteristics of running stride does not explain differences in RE; instead, it has been shown that the horizontal force in the braking phase (eccentric loading phase of ground contact in the foot strike) of the running stride is the main factor explaining oxygen consumption. The amount of vertical and mediolateral forces created during ground contact account for a great percentage of the variance in RE; higher mediolateral forces are associated with athlete with less efficient (higher) RE values (Kyrolainen, Belli, \& Komi, 2001). In support of these findings, instructional interventions to modify running stride which succeed at decreasing stride length and increasing stride rate also fail to change RE, heart rate (HR), or ratings of perceived exertion (RPE) (Craighead, Lehecka, \& King, 2014). This is important for this investigation, as it challenges any assertion that "learning" of running would improve RE.

RE has been also shown to me related to the mechanical factors of muscle. The less flexible a runner as demonstrated in seated sit-and-reach test, the better their RE, presumably due to increased elastic recoil of the muscle stretch-shorten cycle (Trehearn \& Buresh, 2009). These findings were supported by the work of Hunter et al. who found 
that decreased lower limb flexibility and increased lower limb tendon length were associated with better RE (Hunter et al., 2011).This information is important for building a context that RE is strongly related to anatomical characteristics of the subject, which may complicate training interventions which aim to affect RE.

\subsubsection{Heart Rate and Running Economy}

The positive, linear association between heart rate $(\mathrm{HR})$ and $\mathrm{VO}_{2}$ is well documented (Dalleck \& Kravitz, 2006; Strath et al., 2000; Swain, Leutholtz, King, Haas, \& Branch, 1998). However, training can affect maximal heart rate $\left(\mathrm{HR}_{\max }\right)$ with higher values associated with de-training (being out of shape) and lower values associated with increased fitness (Zavorsky, 2000). As discussed above, the relationship between $\mathrm{VO}_{2 \max }$ and RE is highly contested, which complicates the relationship of RE to HR. Binnie et al. did find that improvements in HR at submaximal effort and like factors such as blood lactate concentrations (BLa) occurred simultaneously with worsening (increase in $\mathrm{VO}_{2}$ ) in RE. (Binnie et al., 2014). In conflict with this, Pate et al. found that improvements in RE coincide with lower HR (Pate et al., 1992).

\subsubsection{Respiratory Muscle Fatigue, Hypoxia, Altitude and RE}

With a design on reducing respiratory muscle fatigue in swimmers, this study relies heavily on existing literature to dictate to what extent respiratory muscle fatigue, and the training to reduce respiratory muscle fatigue may affect terrestrial exercise economy and capacity. Much research in RE has been conducted implementing environmental hypoxia (low partial pressure of oxygen in inspired air due to high altitude). Exposure to altitude, which can readily be considered an environmental 
stimulus for hypoxia, has been shown to worsen RE $(+7 \%)$ for those previously living at sea level, even after 46 weeks of acclimatization to moderate altitude (2,210-m). (Brothers et al., 2010). Brothers et al.'s findings call into question whether short-term, acute exercise interventions to induce hypercapnia may generate enough stimuli for change, if nearly a year of ambient hypoxia via moderate altitude cannot. This study is unlike the altitude studies in that the participants will have very limited exposure to hypercapnia, versus intermittent environmental exposure to hypoxia via altitude.

Saunders et al. found that 20 days of simulated altitude residence (simulated 2000-3100-m. altitude, 9-12 hours per night while sleeping) with low-altitude training (known as, "live high, train low") can elicit a $\sim 3 \%$ improvement in RE versus both moderate-altitude residence and training, or low-altitude residence and training (Saunders, Telford, et al., 2004). Subjects did not demonstrate a decrease in minute ventilation. They confirmed their findings by exposing a subsequent group (Saunders, Telford, Pyne, Hahn, \& Gore, 2009) of runners to $\sim 50$ days of simulated altitude residence with low-altitude training and found a $3 \%$ decrease in oxygen consumption (3\% improvement in RE). Their increase in time exposure to live-high, train-low hypoxia for runners elicited the same improvement in RE as their shorter intervention length, suggesting that time-at-exposure to hypoxia is not the only factor at play in improving RE. Their findings are complicated by the fact that hemoglobin mass only very slightly, but significantly, improved $(+5 \%, \mathrm{p}=0.01)$, while no improvement in $\mathrm{VO}_{2 \max }$, further suggesting that $\mathrm{RE}$ and $\mathrm{VO}_{2 \max }$ are physiologic variables with a complicated relationship. 


\subsubsection{Controlled Frequency Breath Holding and RE}

While breath-holding during swimming may be thought to elicit hypoxemia, it does not if one hold his/her breath at TLC (Woorons, Gamelin, Lamberto, Pichon, \& Richalet, 2014). Instead hypercapnia (partial pressure of arterial carbon dioxide $>45 \mathrm{mmHg}$ ) ensues. (Woorons et al., 2014). However, holding one's breath for a period of time after complete exhalation (residual volume, RV) does result in exercise-induced hypoxemia, simulating hypoxia (Woorons et al., 2014).

Until now, only one study used CFB training (at TLC) to elicit hypercapnia in swimmers (Lavin et al., 2013). They showed that CFB training improved RE by $6 \%$ and 150 yard swimming performance by $8 \%$. However, these swimmers were recreational swimmers and it may have been quite easy to improve swimming performance and RE in novice swimmers with relatively slow swim times (150 yards short course swim time was initially $157 \pm 27 \mathrm{~s}$ ). This research caveat is known as the "floor effect" in which subjects who are near the bottom in terms of performance have no other direction to go but upward. Thus, any intervention in these subjects may elicit improvements in performance. For this reason, our investigation remains novel and important; if regular hypercapnic training via CFB proves to be a proponent of improved RE in an elite cohort, it may help direct further research in respiratory interventions for improving exercise economy.

It is well-established that the prior training status of a subject will affect RE, and that trained subjects demonstrate superior RE to untrained subjects (J. Daniels, Oldridge, Nagle, \& White, 1978; J. T. Daniels, 1985). For the purposes of comparing the results of 
this investigation to those of Lavin, it is prudent to consider this current subject pool as, "elite," although not as runners, which logically tends to be the population investigated most often in RE research.

To this point, association of RE and swimming performance has not been established. The Lavin et al. paper did not publish statistical association between recreational athlete's RE and swimming performance, although they later mentioned to me that there was none $(r=0.32, p=0.23$, Personal Communication, 2014). This investigation will seek to establish determine if there is an association between RE and 200 yard swimming performance in elite NCAA swimmers.

\subsubsection{Allometric Scaling of RE}

It is common practice to express the $\mathrm{RE}$ value in the form of $\mathrm{VO}_{2}$ per $\mathrm{kg}$ of body mass per unit distance traveled (i.e. $\mathrm{mL} / \mathrm{kg} / \mathrm{km}$ ). However, this body mass $(\mathrm{BM})$ specific scaling has been questioned as valid for comparison because increases in $\mathrm{VO}_{2}$ are not proportional to increases in BM (Bergh, Sjodin, Forsberg, \& Svedenhag, 1991). It has

been substantiated that RE has statistical association with $\mathrm{RE}$ at the $\mathrm{BM}^{-.066}$ or $\mathrm{BM}^{-0.75}$ values rather than just for $\mathrm{BM}^{-1}$ (Saunders, Pyne, et al., 2004a). 
1.4.7 Operational Definitions for literature review

\begin{tabular}{|c|c|c|c|}
\hline Term & Abbr. & Term & Abbr. \\
\hline $\begin{array}{c}\text { Controlled Frequency } \\
\text { Breathing (intervention group) } \\
\text { ( } 2 \text { breaths per } 50-\mathrm{m} \text { length) }\end{array}$ & CFB & $\begin{array}{l}200 \text { yard Swim Performance Time } \\
\text { (seconds) }\end{array}$ & SPT \\
\hline $\begin{array}{c}\text { Running Economy } \\
(\mathrm{ml} / \mathrm{kg} / \mathrm{km} ; \mathrm{kcal} / \mathrm{km} / \mathrm{km})\end{array}$ & $\mathrm{RE}$ & $\begin{array}{c}\text { Aerobic Capacity } \\
(\mathrm{L} / \mathrm{min} ; \mathrm{mL} / \mathrm{kg} / \mathrm{min})\end{array}$ & $\mathrm{VO}_{2 \max }$ \\
\hline $\begin{array}{l}\text { Stroke-Matched Breathing } \\
\text { (control group) } \\
\text { (10 breaths per 50-m length) }\end{array}$ & SM & $\begin{array}{l}\text { Heart Rate } \\
\text { (beats/min) }\end{array}$ & HR \\
\hline $\begin{array}{l}\text { Global, whole body, oxygen } \\
\text { Consumption } \\
(\mathrm{L} / \mathrm{min}, \mathrm{mL} / \mathrm{kg} / \mathrm{min})\end{array}$ & $\mathrm{VO}_{2}$ & $\begin{array}{l}\text { Rating of Perceived Exertion } \\
\qquad(6 \text { to } 20 \text { scale) }\end{array}$ & RPE \\
\hline
\end{tabular}

\subsection{Research Questions \& Hypotheses}

1. Does a four-week training program of CFB training improve $\mathrm{RE}$ and $\mathrm{VO}_{2 \max }$ in elite NCAA swimmers?

Specific Aim: To investigate response of oxygen utilization at submaximal and maximal efforts while running after CFB intervention.

Hypothesis 1.1: Running Economy will significantly improve by $15 \mathrm{ml} / \mathrm{kg} / \mathrm{km}$ after CFB training and remain unchanged in SM control group as seen in the results of Lavin et al. (2013).

Hypothesis 1.2: $\mathrm{VO}_{2 \max }$ will remain unchanged in either CFB or SM control groups 
2. Does a relationship exist between RE and swimming performance?

Specific Aim: Establish association of $\mathrm{RE}$ as expressed in $\mathrm{VO}_{2}(\mathrm{~mL} / \mathrm{kg} / \mathrm{km})$ with swimming performance in a 200 yard freestyle swimming time trial.

Hypothesis 2: There will be a significant relationship between RE and 200-yd freestyle swim performance.

\subsection{Assumptions}

Certain assumptions have been made throughout our study. We assumed that all participants were healthy and well-conditioned. It was not investigated as to how many of our subjects were also recreational runners. We also assumed that these subjects were able to give a best effort for all their testing sessions. To limit error here, the subjects had to meet three established criteria for attaining $\mathrm{VO}_{2 \max }$ in their testing battery according to ACSM guidelines (ACSM, 2013). Finally, we assumed that these subjects were able to complete all training sessions as necessary. 


\section{CHAPTER 2}

\section{METHODS}

\subsection{Subject Selection}

A convenience sample of NCAA Division I swimmers from the University of Louisville were recruited to participate in this research. Subjects were not chosen randomly. This research has designated all subjects as, "elite," which is requisite of their position on a Division I swim team ranked within the top $10 \%$ for Division I eligible programs. Subjects were an equal, mixed-sex sample. Elite swimmers were desired for this investigation to evaluate whether the results of Lavin et al. (2013) were reproducible in an elite cohort of non-terrestrial athletes.

Whether subjects were more traditionally sprint or endurance swimmers was not of particular interest to investigators, as we desired to acquire as diverse a sample of elite college swimmers as possible.

To be eligible for this study, subjects must have competed for the University of Louisville at some point during the 2013-2014 collegiate swim season. No performancebased metrics such as time-per-distance swum were set for inclusion. The age of subjects was limited to those in agreement with NCAA competition eligibility criteria. Twentyfour subjects were needed for this study. 


\subsection{Settings}

All study intervention and testing was conducted on the University of Louisville campus. Intervention procedures were executed within the Ralph Wright Natatorium. Running economy and $\mathrm{VO}_{2 \max }$ testing were conducted in the Exercise Physiology lab of Crawford Gym.

\subsection{Procedures}

\subsubsection{Pre and Post-Testing}

All subjects attended a pre-participation information session led by study investigators where subjects were asked to read and sign an informed consent document which detailed their responsibilities and risks of study participation.

Pre-testing of athletes consisted of two testing batteries of $\mathrm{RE}$ and $\mathrm{VO}_{2 \max }$. The first was a full familiarization session of the entire running battery procedure (explained below), and then within one week, participated in baseline data battery for RE and $\mathrm{VO}_{2 \max }$. Familiarization and baseline data were compared post-hoc to determine day-today variability and reproducibility. All tests were conducted on the Woodway ELG treadmill (Woodway USA, Waukesha, WI). Metabolic testing was conducted using the PARVO Medics TrueOne 2400 metabolic cart (PARVO Medics, Sandy, UT).

Two pre-intervention testing sessions were administered, the first for test procedure familiarization and then within one week for baseline. At familiarization, subjects were measured for age in years, anthropometrics including height (m), weight $(\mathrm{kg})$, and body composition via hydrostatic weighing. Body composition was calculated according to the Siri and Brozek equations for hydrostatic weighing, with results being 
recorded as the average of the two equations (Brozek, Grande, Anderson, \& Keys, 1963; Siri, 1993). Body composition was measured to allow comparison of anthropometrics of our subjects to other investigations both past and future. Participants were allowed to change clothes to prepare for the running portion of familiarization. All running trials followed the same procedure; running speeds were pre-determined by investigators respective to sex.

Three, 5-minute submaximal running stages were performed. Running at all speeds was conducted on $0 \%$ incline. Submaximal stage one was conducted at $6 \mathrm{mph}$ and $5.5 \mathrm{mph}$ for male and female subjects, respectively. Submaximal stage two was conducted at $7 \mathrm{mph}$ and $6.5 \mathrm{mph}$ for male and female subjects, respectively. The third submaximal stage was conducted at $8 \mathrm{mph}$ male subjects, $7.5 \mathrm{mph}$ for female subjects. Between the first two submaximal stages, and between the second and third submaximal stage, a passive rest period of five to seven minutes was permitted, with all subjects beginning the next stage in no fewer than five, and no more than 6.5 minutes. Participants did not perform any active recovery or physical activity during these inter-stage recovery periods.

At the end of the third submaximal stage, subjects did not participate in a passive recovery period, but rather proceeded on a graded exercise protocol up to maximum volitional fatigue. After the five minutes at the third submaximal stage, the graded exercise progressed every two minutes with a $1.0 \mathrm{mph}$ increase until maximal fatigue was achieved. Indices measured at all running speeds included $\mathrm{HR}, \mathrm{VO}_{2}$, and $\mathrm{RPE}$. Data recorded at maximal intensity included $\mathrm{HR}_{\max }, \mathrm{VO}_{2 \max }$, minute ventilation at maximal 
exercise $\left[\mathrm{VE}_{\max }(\mathrm{L} / \mathrm{min})\right]$, respiratory exchange ratio $\left(\mathrm{RER}_{\max }\right)$, and maximum oxygen pulse $\left(\mathrm{O}_{2} \mathrm{Pulse}_{\max }\right)$.

Economy was calculated as $\mathrm{VO}_{2}$ in $\mathrm{mL} / \mathrm{kg} / \mathrm{km}$ for the final three minutes of each submaximal speed, and then averaged at all speeds to create one value reported as the overall RE. Units for RE was also reported in $\mathrm{kcal} / \mathrm{kg} / \mathrm{km}$.

Post-intervention testing was conducted exactly according to the protocol for both familiarization and baseline sessions. Hydrostatic weighing was recorded only at the familiarization session. Values recorded at familiarization were retained in order to assess day-to-day variability in $\mathrm{RE}$ without training effect to inform on necessary magnitudes for meaningful change. Subjects also completed a $200 \mathrm{~m}$ freestyle swim time trial at maximal volitional effort at BASE and POST in order to investigate correlation between RE and swimming performance as well as to investigate performance improvements.

\subsubsection{Training Intervention}

Subjects, who were divided into two groups, intervention and controls, participated in sixteen $( \pm 2)$ study sessions within a four-week period ( \pm 5 days). Each study session was approximately thirty-five minutes in duration. All subject began with a standardized 1000-m warm up of easy, mixed-stroke swimming.

All subjects participated in the same training intervention workout profile, consisting of 12 repetitions of a 50-m swim completed within a one-minute interval for the first week of the study. Weeks two and three decreased the interval by five seconds, to 55 seconds per rep. An additional five second decrease occurred during the final week 
of training set the intervals at 50 seconds per rep (see Table 3 for the complete training regimen).

The CFB training (intervention) group was instructed self-limit their breathing to two breaths per repetition, resulting in about 24 breaths per workout (only breaths taken during repetitions were counted for workout totals), while controls were allowed to breathe on a stroke-matched basis, breathing every 2-3 strokes accumulating 10-12 breaths per lap. At the end of each workout, all subjects self-reported their number of breaths taken during the workout, as well as reporting their RPE using the 6-20 Borg scale (Borg, 1982). All study training sessions were supervised by at least one member of the University of Louisville swimming coaching staff.

\subsubsection{Research Design}

The research design implemented for this study was a pre-post test design with control group. This was a quasi-experimental design in which a convenient sample of elite college swimmers was used. To examine changes in $\mathrm{RE}$ and $\mathrm{VO}_{2 \max }$, a $2 \times 3$ repeated measures analysis of variance was used. The independent variable was the training program $[$ Experimental Group $=$ CFB training group; Control group $=$ stroke matched (SM) group] and the number of measurements per variable (three measurements per variable: familiarization session, baseline, and post-testing). The Lee notation was represented as: $\mathrm{S}_{12} \cdot\left(\mathrm{G}_{2}\right) \cdot \mathrm{T}_{3}$ in which subjects were nested within group (2 groups, CFB, SM) and crossed with time (familiarization, baseline, post-testing). 


\subsubsection{Statistical Analysis}

Sample size calculation was estimated from the mean overall changes for RE with and between groups from Lavin et al. (2013). Using online statistical software (G*Power Version 3.1.7, Universität Kiel, Germany), the following was calculated for the withinbetween interaction for repeated measures ANOVA: statistical power was set at $80 \%$, type I error rate at $5 \%(\alpha=0.05)$, correlation among repeated measures $=0.90$, and effect size $f=0.0135$. A total of 24 subjects was estimated. Twenty six subjects matriculated into the study to allow for an approximate $10 \%$ attrition rate.

The data was analyzed with the SPSS statistical software package (SPSS Version 21.0, IBM SPSS Statistics Inc., Chicago, IL). Statistical significance was be declared when $\mathrm{p}<0.05$ unless otherwise noted.

To compare groups at baseline, independent $t$-tests were performed. For the variables that were not normally distributed, a Mann-Whitney U Test was used to compare groups. To compare cardiopulmonary variables from the graded exercise test between familiarization and baseline sessions, paired $t$-tests were used. If the variables were not normally distributed, a Wilcoxon Signed Rank test was used.

The repeated measures analyses of variances were used to assess statistical significance of results post-intervention versus baseline with a Bonferroni correction. Pearson product moment correlations were performed for establishing relationships of swimming performance time to RE.

Indices of responsiveness to $\mathrm{CFB}$ training was calculated according to previous methods (Kim, Mayo, Carli, Montgomery, \& Zavorsky, 2009; Salbach et al., 2001). 
Effect size (ES) was defined as the mean change of the variable between baseline and post-training divided by the SD of the variable at baseline. An effect size of 0.0 to 0.2 was considered trivial, 0.2 to 0.5 was small, 0.5 to 0.8 was moderate, and 0.8 and above was strong. The standardized response mean (SRM) was calculated as the average change divided by the SD of the change. The $t$-statistic was defined as the mean change of the variable between base-line and post training divided by the standard error (which is the SD divided by the square root of the sample size).

For the dependent variables that were not altered between familiarization and baseline sessions, the day-to-day coefficient of variation was calculated as the mean of the two trials divided by the standard deviation of the two trials x 100. Measurement error (otherwise known as the typical error or the within subject standard deviation) was calculated as the square root of the within-subjects error variance (i.e., the within-subject standard deviation) derived from a repeated measures ANOVA. Reproducibility was defined as $2.77 \times$ the measurement error (Bland \& Altman, 1996). That is, the difference between two measurements obtained on different days for the same subject is expected to be less than 2.77 times the within-subject standard deviation for $95 \%$ of pairs of observations (Bland \& Altman, 1996). Since the calculation of reproducibility may be considered too stringent, the smallest meaningful change was reported as half of the reproducibility (Hopkins, 2000).

\subsubsection{Data Management and Storage}

All data for RE was recorded digitally within the hard drive associated with the PARVO metabolic cart, and redundantly printed after each stage for all subjects. RPE 
values and between-stage recovery time values were recorded manually by investigators during the test. All data pertaining to the study was kept within a locked room in a locked filing cabinet with access granted only to the investigators managing the study. 


\section{CHAPTER 3}

\section{RESULTS}

Twenty-five swimmers from the University of Louisville completed the familiarization and baseline sessions. Table 1 depicts the subject characteristics. No statistically significant difference existed between groups or between sexes. The 200 yard freestyle swimming times at the baseline session (short course) for all 25 subjects was 115 (SD 7) seconds (range 104 to 129 seconds). There was a mean day-to-day coefficient of variation of $1.4 \%$ (SD $1.6 \%$ ) in swim times between the familiarization and baseline sessions. This equates to a day-to-day typical error of 1.6 seconds for the 200 yard race (day-to-day reproducibility $=4.5$ seconds; smallest meaningful change $=2.2$ seconds)

Table 2 depicts the cardiopulmonary data obtained from treadmill testing of all subjects between familiarization and baseline sessions. The only dependent variables that showed a difference between these two sessions was running economy $(\mathrm{mL} / \mathrm{kg} / \mathrm{km}$, $\mathrm{p}=0.01)$, energy cost $(\mathrm{kcal} / \mathrm{kg} / \mathrm{km}, \mathrm{p}=0.02)$ and $\mathrm{HR}_{\max }($ beats $/ \mathrm{min}, \mathrm{p}=0.03)$, although all were small changes and likely not meaningful due to all having trivial effect sizes.

Table 3 depicts training results of each group. Four of the 25 subjects failed to complete all of their follow-up testing. One left town and was not able to return to testing, while the other three decided that it was no longer worth their time to participate 
in the study. There were no significant changes in any dependent variable, suggesting that neither groups experienced any measurable physiological changes.

Since there were no meaningful differences between most dependent variables between familiarization and baseline sessions (Table 2), we were then interested in the day-to-day variability and other similar indices for implementation in future studies. These indices of reproducibility are presented in Table 4.

There was no significant association between RE and 200-yd swimming times $(\mathrm{n}=25, \mathrm{r}=-0.25, \mathrm{p}=0.23)$ at baseline. However, $69 \%$ of the variance in aerobic capacity was accounted for by difference in swimming times (Equation 1).

Equation 1: 200-yd swim time $(\mathrm{s})=-6.87 \cdot\left(\mathrm{VO}_{2 \max }\right.$ in $\left.\mathrm{L} / \mathrm{min}\right)+142.8$, SEE 3.8, $\mathrm{p}<0.01$ 


\section{CHAPTER 4}

\section{DISCUSSION}

\subsection{Discussion Overview}

The purpose of this study was to assess whether CFB training can improve either $\mathrm{RE}$ or $\mathrm{VO}_{2 \max }$ among elite, college-aged swimmers. This investigation did not find any improvements in $\mathrm{RE}$ or $\mathrm{VO}_{2 \max }$ in either group.

This is the first study that evaluated the effects of CFB training on RE in an elite cohort of swimmers. The previous investigation of this kind was limited to recreational multi-sport athletes (Lavin et al. 2013). Our failure to find any significant change in RE from the CFB intervention conflicts with the findings of Lavin et al. who found an improvement (that is to say, lower $\mathrm{VO}_{2}$ at a given sub-maximal running velocity) in $\mathrm{RE}$ of $\sim 15 \mathrm{ml} / \mathrm{kg} / \mathrm{km}$, or $\sim 6 \%$. As Lavin's authors noted, their demonstration of change to performance was presumed to be a not-yet understood improvement in peripheral, vascular physiology. Just what precipitated the results in the Lavin cohort but not this one is likely due to the difficulty of eliciting change in the elite athlete, for whom the threshold for improvement is extremely high, with the potential for improvement very small.

With that said, the failure to achieve significant improvement in RE is consistent with some previous research that indicates that RE is not easily improved, nor perturbed, 
by factors of training stimulus alone. An overload of training volume of up to $50 \%$ among well-trained triathletes cannot significantly affect RE (Palazzetti et al., 2005). Palazzetti et al. utilized an intervention lasting three weeks, which is of similar duration to this investigation; it is possible that our intervention was not of great enough duration, despite significant results in a novice cohort as demonstrated elsewhere (Lavin et al., 2013).

Brothers and coworkers demonstrated that nearly a year spent at $6,000-\mathrm{ft}$ of altitude demonstrated a worsening (that is to say, higher $\mathrm{VO}_{2}$ at a given sub-maximal running velocity) in $\mathrm{RE}$, suggesting that physiological improvements in $\mathrm{RE}$ are slow to change due to environmental factors (Brothers et al., 2010).

\subsection{Normal values for $R E$}

Later, Morgan and colleagues determined that in runners who competed in the 1984 U.S. Olympic trials had a mean RE of 182 (SD 9) $\mathrm{mL} / \mathrm{kg} / \mathrm{km}$ with a range of 162 to $196 \mathrm{~mL} / \mathrm{kg} / \mathrm{km}$ (Morgan et al., 1995). In contrast, this study used swimmers, and their RE ranged from 182 to $224 \mathrm{~mL} / \mathrm{kg} / \mathrm{km}$ with mean of 203 (SD 11) mL/kg/km. Our elite cohort of swimmers demonstrated inferior RE to an elite running cohort. In fact, the mean RE in this swimming cohort was similar to the RE of physical education majors [202 (SD 12) $\mathrm{mL} / \mathrm{kg} / \mathrm{km}$ ] not accustomed to run training (Morgan et al., 1995). Our subjects did demonstrate a much narrower range among their RE values than in the elite runners of Morgan et al., suggesting they were a very physiologically similar group. Additionally, the "poor" RE determined my Mooses and colleagues (Mooses et al., 2014) found that 
the average RE of elite Kenyan runners was 229 (SD 13), which supports the assertion that $\mathrm{RE}$ is only one variable of many that predict running performance.

Our research found that the reproducibility in RE was $11.8 \mathrm{~mL} / \mathrm{kg} / \mathrm{km}$. That is, the difference between two measurements obtained on different days for the same subject is expected to be less than 2.77 times the within-subject standard deviation (Bland \& Altman, 1996). The within subject standard deviation is otherwise known as the typical error. Thus, with an observed difference in RE between day 1 and day 2 differs by more than $\pm 11.8 \mathrm{~mL} / \mathrm{kg} / \mathrm{km}$, there is a $97.5 \%$ probability that the change is indeed real (39 to 1 odds), and only a $2.5 \%$ probability that it is not a true change. According to Will Hopkins, this degree of certainty about a true change unrealistic (Hopkins, 2000). He suggests that half the limit of agreement seems a more reasonable threshold; when an observed change in RE differs by more than $\pm 5.9 \mathrm{~mL} / \mathrm{kg} / \mathrm{min}$ in our cohort of swimmers, there is an $84 \%$ probability that the change is indeed real (5 to 1 odds), and only a $16 \%$ probability that it is not a true change. This is approximately $1.5 \mathrm{x}$ the typical error (i.e. $1.5 \mathrm{x}$ the measurement error) which is a more realistic threshold according to Hopkins. Thus, the smallest meaningful day-to-day change in RE converted to a percentage would be about $3 \%$, which is similar its day-to-day coefficient of variation of $2.4 \%$ (Table 5 ).

This is in contrast to Saunders et al. who state that among elite runners, changes in RE greater than $2.4 \%$ should be considered meaningful (Saunders, Pyne, Telford, \& Hawley, 2004b; Saunders et al., 2009). Shaw et al. demonstrated that the within subject standard deviation (i.e. the typical error) for both $\mathrm{RE}(\mathrm{mL} / \mathrm{kg} / \mathrm{km})$ and energy cost $(\mathrm{kcal} / \mathrm{kg} / \mathrm{km}$ ) was also 3-4\% (Shaw, Ingham, Fudge, \& Folland, 2013) in their cohort. 


\subsection{RE and Swimming Performance}

This study found no association between RE and 200 yard swimming performance, which agrees with Lavin's study on novice swimmers (Lavin et al., 2013). In light of this, we conclude that RE is not a valid measure of swimming performance in swimmers. Thereby, it behooves further research to seek other surrogate markers for swimming performance among swimmers. Failure to demonstrate association between RE and swimming performance in a large sample size of relatively homogenous swimmers $(\mathrm{n}=25)$, however, should warrant the cessation of RE investigations among swimmers, as its relevance could be poor.

Ideally, economy while swimming would have been assessed instead of running economy; our laboratory is at this time unequipped to perform cardiopulmonary testing underwater. For this reason, RE was the most accessible, similar testing method. RE, however, still bears importance on the emerging population of crossover athletes, particularly in the multi-sport arena such as triathlon, for whom running is a regular portion of their training, but still includes swimming.

A strong negative relationship was demonstrated between $\mathrm{VO}_{2 \max }(\mathrm{L} / \mathrm{min})$ and 200 yard swimming performance indicating that as $\mathrm{VO}_{2 \max }(\mathrm{L} / \mathrm{min})$ increases, the time to complete a 200 yard swim decreases $(r=-0.84, \mathrm{p}<0.05)$. This is in agreement with the findings that swimmer's absolute $\mathrm{VO}_{2 \max }(\mathrm{L} / \mathrm{min})$ is an important predictor of swimming performance (Butts et al., 1991). As well, this provides for insight on whether a swimmer's time trial performance should be regarded as comparable, superior, or inferior to that of their maximal aerobic capacity. 


\subsection{Familiarization trials for RE testing}

Our investigation will inform future research on particular necessity of familiarization for investigating $\mathrm{VO}_{2 \max }$ and $\mathrm{RE}$ in elite swimmers. No statistically significant differences were found between familiarization and baseline sessions (see Table 3), which is strongly suggestive that swimmers, although not a population who regularly runs, do not require familiarization to a treadmill or metabolic cart. nvestigators in the future can forego familiarization and begin with baseline testing.

\subsection{Day-to-day variability in $R E$}

In light of finding no significant improvement from a CFB intervention, our investigation expanded its aims to assess the day-to-day variation in several cardiopulmonary parameters. The day-to-day coefficient of variation of $2.4 \%$ in RE $(\mathrm{ml} / \mathrm{kg} / \mathrm{km})$ demonstrates that $\mathrm{RE}$ is a stable measure, even in swimmers, who are unaccustomed to running.

Other research in day-to-day variability of RE conflict with our findings, as well as with one another. Zavorsky and colleagues found that the mean day-to-day variability of RE in an elite, homogeneous male running cohort (mostly college runners) was 2.5\% $[$ mean $=196($ SD 13), range $=166$ to $232 \mathrm{~mL} / \mathrm{kg} / \mathrm{km}]$ (Zavorsky, Montgomery, \& Pearsall, 1998). These findings are similar to other research by Morgan et al., who found the variation of $\mathrm{RE}$ is about $1.3 \%$ (range $=0.3$ to $4.4 \%$ ) in well trained runners (Morgan, Martin, Krahenbuhl, \& Baldini, 1991). Pereira et al. investigated the day-to-day variability (the day-to-day coefficient of variation) in RE among highly-trained and moderately-trained male runners, found to be $1.8 \%$ and $2 \%$ respectively and not 
statistically different $(\mathrm{p}>0.05)$ (Pereira \& Freedson, 1997). These conflicting findings suggests that the variability of RE may differ greatly in research despite a homogenous pool of subjects. Morgan et al. explicitly states their strict control of some testing procedures that may have contributed to their more narrow variation; these differences will be discussed more thoroughly in limitations below. Still, further research is needed to explain the differences uncovered here.

\subsection{Limitations}

Authors of this study recognize it has some limitations. While the results of this study bear important information on athletic testing and coaching at large, we recognize that CFB training among elite swimmers is only immediately relevant to like populations.

Subjects of this study were elite swimmers all retained by the NCAA Division I swimming team of the University of Louisville, and thus are not a randomly obtained sample. Subjects identified as Caucasian/White, and only one identified as Hispanic/Latino; race of subjects was a known delimitation among our convenience sample. Research suggests that race may substantially influence $\mathrm{VO}_{2 \max }($ Ceaser, Fitzhugh, Thompson, \& Bassett, 2013). Ceaser et al. found that $\mathrm{VO}_{2 \max }$ was significantly higher for Mexican Americans than for non-Hispanic Whites, with race explaining a significant component of the variance $(19 \%, \mathrm{p}<0.01)$ in $\mathrm{VO}_{2 \max }$. This piece of literature observed that the intersection of race with physical activity and degree of exercise intensity cumulatively accounted for a lot of difference in $\mathrm{VO}_{2 \max }$. In light of this, our investigation cannot be considered an ethnically diverse nor representative sample of the population. 
As is true of most research conducted on athletes whose training volume vacillates seasonally, the subjects of this study underwent research at the very beginning of their pre-season training. Therefore, we tracked training volume of athletes during the study in order to account for the possibility that increase in training volume in general, not from this intervention specifically, may have affected $\mathrm{VO}_{2 \max }$ or $\mathrm{RE}$. In spite of this, previous research has demonstrated that volume overload in and of itself does not affect RE (Palazzetti et al., 2005). Even still, a control group was retained in order to comparatively indicate augmentation in either $\mathrm{VO}_{2 \max }$ or $\mathrm{RE}$ due to training alone. While internal validity may have benefitted from an experimental design wherein subjects only underwent CFBH or SM intervention, it is unrealistic to the nature of an elite swimmer's training and should be considered supportive of the external validity of this research.

Findings may be limited by the periodical timing of the study. This intervention was implemented during the subjects' offseason and into the beginning weeks of preseason. Aerobic performance of swimmers has been shown to vary throughout a swimmer's training season (Perini et al., 2006). This phase of training limits relevance of results to the period of training of other swimmers.

Our failure to reproduce Lavin's findings of improvement in RE may be explained by the physiological differences in our cohort. However, the intensity of the exercise may not have been sufficient to elicit performance results in an elite swimming population (Mujika et al., 1996). Future investigations of a similar sort may consider a longer intervention, although previous research does not guarantee that increased volume will improve swimming performance (Costill et al., 1991), and therefore may also fail to affect RE. 
This study incurred a limitation in procedure. Investigators did not control for shoe selection of subjects between trials. Shoe style immediately and significantly alters RE (Reeves et al., 2014; Sobhani et al., 2014). Insignificant results may be confounded by the failure to control for shoe selection. Replication of this investigation should control for shoe model in subjects between all trials. To this point, subjects frequently reported experience of shin splints while running. This qualitative observation, while beyond the analysis of statistical significance, should be considered as a contextual problem.

In conclusion, RE in swimmers has not been found to be a significant predictor of swimming performance time, nor is it changed significantly with a four week intervention of CFB training in elite swimmers. The day-to-day variability in $\mathrm{RE}(\mathrm{mL} / \mathrm{kg} / \mathrm{km})$, energy cost $(\mathrm{kcal} / \mathrm{kg} / \mathrm{km})$, and $\mathrm{VO}_{2 \max }(\mathrm{L} / \mathrm{min})$ was found to be between 2.4 and 3.4\%. Further research of CFB training in elite swimmers to improve RE is likely not warranted, although further directions should continue to investigate RE in multisport athletes who participate both in swimming and in running. 


\section{REFERENCES}

Anderson, T. (1996). Biomechanics and running economy. Sports Medicine, 22(2), 76-89.

Andrew, G. M., Becklake, M. R., Guleria, J. S., \& Bates, D. V. (1972). Heart and lung functions in swimmers and nonathletes during growth. Journal of Applied Physiology, 32(2), 245251.

Barnes, K. R., \& Kilding, A. E. (2014). Strategies to Improve Running Economy. Sports Medicine. doi: 10.1007/s40279-014-0246-y

Bergh, U., Sjodin, B., Forsberg, A., \& Svedenhag, J. (1991). The relationship between body mass and oxygen uptake during running in humans. Medicine \& Science in Sports and Exercise, 23(2), 205-211.

Binnie, M. J., Dawson, B., Arnot, M. A., Pinnington, H., Landers, G., \& Peeling, P. (2014). Effect of sand versus grass training surfaces during an 8-week pre-season conditioning programme in team sport athletes. Journal of Sports Science, 32(11), 1001-1012. doi: $10.1080 / 02640414.2013 .879333$

Bland, J. M., \& Altman, D. G. (1996). Measurement error. BMJ, 312(7047), 1654.

Borg, G. A. (1982). Psychophysical bases of perceived exertion. Medicine \& Science in Sports and Exercise, 14(5), 377-381.

Brothers, M. D., Doan, B. K., Zupan, M. F., Wile, A. L., Wilber, R. L., \& Byrnes, W. C. (2010). Hematological and physiological adaptations following 46 weeks of moderate altitude residence. High Altitude Medical Biology, 11(3), 199-208. doi: 10.1089/ham.2009.1090 
Brozek, J., Grande, F., Anderson, J. T., \& Keys, A. (1963). Densitometric Analysis of Body Composition: Revision of Some Quantitative Assumptions. Annals of New York Academy of Science, 110, 113-140.

Butts, N. K., Henry, B. A., \& McLean, D. (1991). Correlations between VO2max and performance times of recreational triathletes. Journal of Sports Medicine \& Physical Fitness, 31(3), 339-344.

Bye, P. T., Farkas, G. A., \& Roussos, C. (1983). Respiratory factors limiting exercise. Annual Review of Physiology, 45, 439-451. doi: 10.1146/annurev.ph.45.030183.002255

Ceaser, T. G., Fitzhugh, E. C., Thompson, D. L., \& Bassett, D. R., Jr. (2013). Association of physical activity, fitness, and race: NHANES 1999-2004. Medicine \& Science in Sports and Exercise, 45(2), 286-293. doi: 10.1249/MSS.0b013e318271689e

Conley, D. L., \& Krahenbuhl, G. S. (1980). Running economy and distance running performance of highly trained athletes. Medicine \& Science in Sports and Exercise, 12(5), 357-360.

Conley, D. L., Krahenbuhl, G. S., Burkett, L. N., \& Millar, A. L. (1981). Physiological correlates of female road racing performance. Research Quarterly for Exercise \& Sport, 52(4), 441448. doi: 10.1080/02701367.1981.10607889

Costill, D. L., Thomas, R., Robergs, R. A., Pascoe, D., Lambert, C., Barr, S., \& Fink, W. J. (1991). Adaptations to swimming training: influence of training volume. Medicine \& Science in Sports and Exercise, 23(3), 371-377.

Craighead, D., Lehecka, N., \& King, D. L. (2014). A novel running mechanic's class changes kinematics but not running economy. Journal of Strength \& Conditioning Research. doi: 10.1519/JSC.0000000000000500

Dalleck, L. C., \& Kravitz, L. (2006). Relationship Between \%Heart Rate Reserve And \%VO2 Reserve During Elliptical Crosstrainer Exercise. Journal of Sports Science and Medicine, 5(4), 662-671. 
Daniels, J., Oldridge, N., Nagle, F., \& White, B. (1978). Differences and changes in VO2 among young runners 10 to 18 years of age. Medicine \& Science in Sports and Exercise, 10(3), 200-203.

Daniels, J. T. (1985). A physiologist's view of running economy. Medicine \& Science in Sports and Exercise, 17(3), 332-338.

di Prampero, P. E. (2003). Factors limiting maximal performance in humans. European Journal of Applied Physiology, 90(3-4), 420-429. doi: 10.1007/s00421-003-0926-z

Gjedde, A. (2005). The pathways of oxygen in brain. II. Competitions for cytochrome c oxidase and NOS are keys to flow-metabolism coupling. Advances in Experimental Medicine and Biology, 566, 277-283. doi: 10.1007/0-387-26206-7_37

Grant, S., Craig, I., Wilson, J., \& Aitchison, T. (1997). The relationship between 3 km running performance and selected physiological variables. Journal of Sports Science, 15(4), $403-$ 410. doi: $10.1080 / 026404197367191$

Gupta, S., \& Goswami, A. (2001). A comparative study of cardiovascular stress during different swimming strokes. Indian Journal of Physiology \& Pharmacology, 45(2), 245-248.

Hopkins, W. G. (2000). Measures of reliability in sports medicine and science. Sports Medicine, $30(1), 1-15$

Hunter, G. R., Katsoulis, K., McCarthy, J. P., Ogard, W. K., Bamman, M. M., Wood, D. S., .. . Newcomer, B. R. (2011). Tendon length and joint flexibility are related to running economy. Medicine and Science in Sports and Exercise, 43(8), 1492-1499. doi: 10.1249/MSS.0b013e318210464a

Kim, D. J., Mayo, N. E., Carli, F., Montgomery, D. L., \& Zavorsky, G. S. (2009). Responsive measures to prehabilitation in patients undergoing bowel resection surgery. Tohoku Journal of Experimental Medicine, 217(2), 109-115.

Kong, P. W., \& de Heer, H. (2008). Anthropometric, gait and strength characteristics of kenyan distance runners. Journal of Sports Science and Medicine, 7(4), 499-504. 
Kyrolainen, H., Belli, A., \& Komi, P. V. (2001). Biomechanical factors affecting running economy. Medicine and Science in Sports and Exercise, 33(8), 1330-1337.

Lavin, K. M., Guenette, J. A., Smoliga, J. M., \& Zavorsky, G. S. (2013). Controlled-frequency breath swimming improves swimming performance and running economy. Scandinavian Journal of Medicine and Science in Sports. doi: 10.1111/sms.12140

Luhtanen, P., Rahkila, P., Rusko, H., \& Viiasalo, J. T. (1990). Mechanical work and efficiency in treadmill running at aerobic and anaerobic thresholds. Acta Physiologica Scandinavica, 139(1), 153-159. doi: 10.1111/j.1748-1716.1990.tb08908.x

McKay, E. E., Braund, R. W., Chalmers, R. J., \& Williams, C. S. (1983). Physical work capacity and lung function in competitive swimmers. British Journal of Sports Medicine, 17(1), 27-33.

Midgley, A. W., McNaughton, L. R., \& Jones, A. M. (2007). Training to enhance the physiological determinants of long-distance running performance: can valid recommendations be given to runners and coaches based on current scientific knowledge? Sports Medicine, 37(10), 857-880.

Mooses, M., Mooses, K., Haile, D. W., Durussel, J., Kaasik, P., \& Pitsiladis, Y. P. (2014). Dissociation between running economy and running performance in elite Kenyan distance runners. Journal of Sports Science, 1-9. doi: 10.1080/02640414.2014.926384

Morgan, D. W., Bransford, D. R., Costill, D. L., Daniels, J. T., Howley, E. T., \& Krahenbuhl, G. S. (1995). Variation in the aerobic demand of running among trained and untrained subjects. Medicine and Science in Sports and Exercise, 27(3), 404-409.

Morgan, D. W., \& Daniels, J. T. (1994). Relationship between VO2max and the aerobic demand of running in elite distance runners. International Journal of Sports Medicine, 15(7), 426429. doi: $10.1055 / \mathrm{s}-2007-1021082$

Morgan, D. W., Martin, P. E., \& Krahenbuhl, G. S. (1989). Factors affecting running economy. Sports Med, 7(5), 310-330. 
Mujika, I., Busso, T., Lacoste, L., Barale, F., Geyssant, A., \& Chatard, J. C. (1996). Modeled responses to training and taper in competitive swimmers. Medicine and Science in Sports and Exercise, 28(2), 251-258.

Padilla, S., Bourdin, M., Barthelemy, J. C., \& Lacour, J. R. (1992). Physiological correlates of middle-distance running performance. A comparative study between men and women. European Journal of Applied Physiology \& Occupational Physiology, 65(6), 561-566.

Palazzetti, S., Margaritis, I., \& Guezennec, C. Y. (2005). Swimming and cycling overloaded training in triathlon has no effect on running kinematics and economy. International Journal of Sports Medicine, 26(3), 193-199. doi: 10.1055/s-2004-817923

Pate, R. R., Macera, C. A., Bailey, S. P., Bartoli, W. P., \& Powell, K. E. (1992). Physiological, anthropometric, and training correlates of running economy. Medicine and Science in Sports and Exercise, 24(10), 1128-1133.

Pereira, M. A., \& Freedson, P. S. (1997). Intraindividual variation of running economy in highly trained and moderately trained males. International Journal of Sports Medicine, 18(2), 118-124. doi: 10.1055/s-2007-972606

Perini, R., Tironi, A., Cautero, M., Di Nino, A., Tam, E., \& Capelli, C. (2006). Seasonal training and heart rate and blood pressure variabilities in young swimmers. European Journal of Applied Physiology, 97(4), 395-403. doi: 10.1007/s00421-006-0174-0

Reeves, K. A., Corbett, J., \& Barwood, M. J. (2014). Barefoot running improves economy at high intensities and peak treadmill velocity. Journal of Sports Medicine and Physical Fitness.

Salbach, N. M., Mayo, N. E., Higgins, J., Ahmed, S., Finch, L. E., \& Richards, C. L. (2001). Responsiveness and predictability of gait speed and other disability measures in acute stroke. Archives of Physical Medicine and Rehabilitation, 82(9), 1204-1212. doi: 10.1053/apmr.2001.24907

Santos-Concejero, J., Granados, C., Irazusta, J., Bidaurrazaga-Letona, I., Zabala-Lili, J., Tam, N., \& Gil, S. M. (2013). Differences in ground contact time explain the less efficient running 
economy in north african runners. Biology and Sport, 30(3), 181-187. doi:

$10.5604 / 20831862.1059170$

Santos-Concejero, J., Olivan, J., Mate-Munoz, J. L., Muniesa, C., Montil, M., Tucker, R., \& Lucia, A. (2014). Gait Cycle Characteristics and Running Economy in Elite Eritrean and European Runners. International Journal of Sports Physiology \& Perform. doi:

10.1123/ijspp.2014-0179

Sarro, K. J., Silvatti, A. P., \& Barros, R. M. (2008). Coordination between ribs motion and thoracoabdominal volumes in swimmers during respiratory maneuvers. Journal of Sports Science and Medicine, 7(2), 195-200.

Saunders, P. U., Pyne, D. B., Telford, R. D., \& Hawley, J. A. (2004a). Factors affecting running economy in trained distance runners. Sports Medicine, 34(7), 465-485.

Saunders, P. U., Pyne, D. B., Telford, R. D., \& Hawley, J. A. (2004b). Reliability and variability of running economy in elite distance runners. Medicine and Science in Sports and Exercise, 36(11), 1972-1976.

Saunders, P. U., Telford, R. D., Pyne, D. B., Cunningham, R. B., Gore, C. J., Hahn, A. G., \& Hawley, J. A. (2004). Improved running economy in elite runners after 20 days of simulated moderate-altitude exposure. Journal of Applied Physiology (1985), 96(3), 931937. doi: 10.1152/japplphysiol.00725.2003

Saunders, P. U., Telford, R. D., Pyne, D. B., Hahn, A. G., \& Gore, C. J. (2009). Improved running economy and increased hemoglobin mass in elite runners after extended moderate altitude exposure. Journal of Science in Medicine and Sport, 12(1), 67-72. doi: 10.1016/j.jsams.2007.08.014

Shaw, A. J., Ingham, S. A., Fudge, B. W., \& Folland, J. P. (2013). The reliability of running economy expressed as oxygen cost and energy cost in trained distance runners. Applied physiology, nutrition, and metabolism = Physiologie appliquee, nutrition et metabolisme, 38(12), 1268-1272. doi: 10.1139/apnm-2013-0055 
Siri, W. E. (1993). Body composition from fluid spaces and density: analysis of methods. 1961. Nutrition, 9(5), 480-491; discussion 480, 492.

Sobhani, S., Bredeweg, S., Dekker, R., Kluitenberg, B., van den Heuvel, E., Hijmans, J., \& Postema, K. (2014). Rocker shoe, minimalist shoe, and standard running shoe: a comparison of running economy. Journal of Science in Medicine and Sport, 17(3), 312316. doi: $10.1016 /$ j.jsams.2013.04.015

Strath, S. J., Swartz, A. M., Bassett, D. R., Jr., O'Brien, W. L., King, G. A., \& Ainsworth, B. E. (2000). Evaluation of heart rate as a method for assessing moderate intensity physical activity. Medicine and Science in Sports and Exercise, 32(9 Suppl), S465-470.

Swain, D. P., Leutholtz, B. C., King, M. E., Haas, L. A., \& Branch, J. D. (1998). Relationship between $\%$ heart rate reserve and $\% \mathrm{VO} 2$ reserve in treadmill exercise. Medicine and Science in Sports and Exercise, 30(2), 318-321.

Tartaruga, M. P., Brisswalter, J., Mota, C. B., Alberton, C. L., Gomenuka, N. A., \& PeyreTartaruga, L. A. (2013). Mechanical work and long-distance performance prediction: the influence of allometric scaling. Journal of Human Kinetics, 38, 73-82. doi: 10.2478/hukin-2013-0047

Trehearn, T. L., \& Buresh, R. J. (2009). Sit-and-reach flexibility and running economy of men and women collegiate distance runners. Journal of Strength \& Conditioning Research, 23(1), 158-162. doi: 10.1519/JSC.0b013e31818eaf49

Weston, A. R., Mbambo, Z., \& Myburgh, K. H. (2000). Running economy of African and Caucasian distance runners. Medicine and Science in Sports and Exercise, 32(6), 11301134.

Woorons, X., Gamelin, F. X., Lamberto, C., Pichon, A., \& Richalet, J. P. (2014). Swimmers can train in hypoxia at sea level through voluntary hypoventilation. Respiratory Physiology and Neurobiology, 190, 33-39. doi: 10.1016/j.resp.2013.08.022 
Yoshida, T., Udo, M., Iwai, K., \& Yamaguchi, T. (1993). Physiological characteristics related to endurance running performance in female distance runners. Journal of Sports Science, 11(1), 57-62. doi: 10.1080/02640419308729964

Zavorsky, G. S. (2000). Evidence and possible mechanisms of altered maximum heart rate with endurance training and tapering. Sports Medicine, 29(1), 13-26.

Zavorsky, G. S., Montgomery, D. L., \& Pearsall, D. J. (1998). Effect of intense interval workouts on running economy using three recovery durations. European Journal of Applied Physiology \& Occupational Physiology, 77(3), 224-230.

Zinman, R., \& Gaultier, C. (1987). Maximal static pressures and lung volumes in young female swimmers: one year follow-up. Pediatric Pulmonology, 3(3), 145-148. 
6.1 TABLE 1 Participant Characteristics

\begin{tabular}{|c|c|c|c|c|}
\hline & $\begin{array}{c}\text { Stroke- } \\
\text { matched group } \\
(\mathrm{n}=13,7 \text { men })\end{array}$ & $\begin{array}{c}\text { Controlled } \\
\text { Frequency } \\
\text { Breathing } \\
\text { group } \\
(\mathrm{n}=12,7 \text { men })\end{array}$ & $p$-value & $\begin{array}{c}\text { Combined } \\
\text { Mean } \\
(\mathrm{n}=25)\end{array}$ \\
\hline \multicolumn{5}{|l|}{ Variables } \\
\hline Age (yrs) & $\begin{array}{l}19.5(1.3) \\
{[18 \text { to } 22]}\end{array}$ & $\begin{array}{l}20.1(1.1) \\
{[19 \text { to } 22]}\end{array}$ & 0.13 & $\begin{array}{l}19.8(1.2) \\
{[18 \text { to } 22]}\end{array}$ \\
\hline Weight $(\mathrm{kg})$ & $\begin{array}{c}78(10) \\
{[63 \text { to } 94]}\end{array}$ & $\begin{array}{c}77(11) \\
{[57 \text { to } 90]}\end{array}$ & 0.71 & $\begin{array}{c}78(10) \\
{[57 \text { to } 94]}\end{array}$ \\
\hline Height (cm) & $\begin{array}{c}176(8) \\
{[162 \text { to } 189]}\end{array}$ & $\begin{array}{c}178(11) \\
{[156 \text { to } 191]}\end{array}$ & 0.64 & $\begin{array}{c}177(9) \\
{[156 \text { to } 191]}\end{array}$ \\
\hline$B M I\left(\mathrm{~kg} / \mathrm{m}^{2}\right)$ & $\begin{array}{c}25.2(2.0) \\
{[22.6 \text { to } 29.0]}\end{array}$ & $\begin{array}{c}24.2(1.7) \\
{[21.7 \text { to } 27.4]}\end{array}$ & 0.19 & $\begin{array}{c}24.7(1.9) \\
{[21.7 \text { to } 29.0]}\end{array}$ \\
\hline $\begin{array}{l}\text { Bodyfat } \\
\text { percentage }\end{array}$ & $\begin{array}{c}17(6) \\
{[9 \text { to } 26]}\end{array}$ & $\begin{array}{c}15(3) \\
{[10 \text { to } 22]}\end{array}$ & 0.50 & $\begin{array}{c}16(5) \\
{[9 \text { to } 26]}\end{array}$ \\
\hline Wing span $(\mathrm{cm})$ & $\begin{array}{c}183(11) \\
{[165 \text { to } 199]}\end{array}$ & $\begin{array}{c}184(13) \\
{[158 \text { to } 199]}\end{array}$ & 0.88 & $\begin{array}{c}183(12) \\
{[158 \text { to } 199]}\end{array}$ \\
\hline $\begin{array}{l}\text { Wing span } \\
\text { divided by } \\
\text { height }\end{array}$ & $\begin{array}{c}1.04(.02) \\
{[0.98 \text { to } 1.06]}\end{array}$ & $\begin{array}{c}1.03(0.02) \\
{[1.00 \text { to } 1.08]}\end{array}$ & 0.39 & $\begin{array}{c}1.03(0.02) \\
{[0.98 \text { to } 1.08]}\end{array}$ \\
\hline $\begin{array}{l}\text { Swimming } \\
\text { performance } \\
\text { time }\end{array}$ & $\begin{array}{c}115.2(7.3) \\
{[105.0 \text { to } 126.5]}\end{array}$ & $\begin{array}{c}113.7(6.6) \\
{[104.5 \text { to } 128.9]}\end{array}$ & 0.61 & $\begin{array}{c}114.5(6.9) \\
{[104.5 \text { to } 128.9]}\end{array}$ \\
\hline
\end{tabular}

Mean (SD), [range]. Non-parametric $t$-tests were used for non-normally-distributed data [age, wing span/height]. Independent $t$-tests were used for all other comparisons. 
6.2 TABLE 2 Experimental design; intervention progression

\begin{tabular}{|c|c|c|c|}
\hline & Intervention & $\begin{array}{c}\text { Stroke-Matched } \\
\text { (control) }\end{array}$ & $\begin{array}{c}\text { Controlled Frequency } \\
\text { Breathing (CFB) }\end{array}$ \\
\hline Week 1 & $\begin{array}{l}12 \times 50 \mathrm{~m} \text { front crawl } \\
\text { on } 1: 00 \mathrm{~min} \text { interval }\end{array}$ & \multirow{3}{*}{$\begin{array}{l}\text { May breathe every 2-3 } \\
\text { strokes (stroke- } \\
\text { matched), } \\
\text { total of } 110-120 \\
\text { breaths per workout }\end{array}$} & \multirow{3}{*}{$\begin{array}{c}\text { May only breathe } 2-3 \\
\text { breaths per } 50 \mathrm{~m} \text { lap } \\
\text { (controlled frequency), } \\
\text { total of } 24-30 \text { breaths } \\
\text { per workout }\end{array}$} \\
\hline Week 2 \& 3 & $\begin{array}{c}12 \times 50 \mathrm{~m} \text { front crawl } \\
\text { on } 0: 55 \mathrm{sec} \text { interval }\end{array}$ & & \\
\hline Week 4 & $\begin{array}{c}12 \times 50 \mathrm{~m} \text { front crawl } \\
\text { on } 0: 50 \mathrm{sec} \text { interval }\end{array}$ & & \\
\hline
\end{tabular}

There were 4 sessions per week. 
6.3 TABLE 3 Cardiopulmonary data obtained from the graded exercise test to volitional exhaustion as well as running economy data

\begin{tabular}{|c|c|c|c|}
\hline & $\begin{array}{l}\text { Familiarization Trial } \\
\qquad(\mathrm{n}=\mathbf{2 5})\end{array}$ & $\begin{array}{l}\text { Baseline Trial } \\
\quad(n=25)\end{array}$ & $p$-value \\
\hline \multicolumn{4}{|l|}{ Variables } \\
\hline $\mathrm{VO}_{2 \max }(\mathrm{L} / \mathrm{min})$ & $\begin{array}{c}4.13(0.77) \\
{[2.93 \text { to } 5.16]}\end{array}$ & $\begin{array}{c}4.12(0.84) \\
{[2.77 \text { to } 5.39]}\end{array}$ & 0.79 \\
\hline $\begin{array}{l}\mathrm{VO}_{2 \max } \\
(\mathrm{mL} / \mathrm{kg} / \mathrm{min})\end{array}$ & $\begin{array}{c}52.9(5.1) \\
{[43.2 \text { to } 60.6]}\end{array}$ & $\begin{array}{c}52.5(5.5) \\
{[39.4 \text { to } 63.1]}\end{array}$ & 0.39 \\
\hline $\mathrm{VE}_{\max }(\mathrm{L} / \mathrm{min})$ & $\begin{array}{c}117(21) \\
{[75 \text { to } 148]}\end{array}$ & $\begin{array}{c}115(24) \\
{[63 \text { to } 149]}\end{array}$ & 0.18 \\
\hline $\mathrm{RER}_{\max }$ & $\begin{array}{c}1.13(0.03) \\
{[1.08 \text { to } 1.19]}\end{array}$ & $\begin{array}{c}1.12(0.05) \\
{[1.01 \text { to } 1.18]}\end{array}$ & 0.17 \\
\hline $\mathrm{HR}_{\max }($ beats/min) & $\begin{array}{c}195(9) \\
{[174 \text { to } 209]}\end{array}$ & $\begin{array}{c}192(10) \\
{[177 \text { to } 210]}\end{array}$ & $0.03 *$ \\
\hline $\begin{array}{l}\text { Oxygen pulse at } \\
\max (\mathrm{mL} / \text { beat })\end{array}$ & $\begin{array}{l}21.9(4.5) \\
{[16 \text { to } 32]}\end{array}$ & $\begin{array}{l}22.1(4.6) \\
{[15 \text { to } 28]}\end{array}$ & 0.66 \\
\hline $\begin{array}{l}\text { Running economy } \\
(\mathrm{mL} / \mathrm{kg} / \mathrm{km})\end{array}$ & $\begin{array}{c}204(12) \\
{[182 \text { to } 224]}\end{array}$ & $\begin{array}{c}201(10) \\
{[183 \text { to } 217]}\end{array}$ & $0.01 *$ \\
\hline $\begin{array}{l}\text { Energy cost } \\
(\mathrm{kcal} / \mathrm{kg} / \mathrm{km})\end{array}$ & $\begin{array}{c}1.01(0.06) \\
{[0.91 \text { to } 1.13]}\end{array}$ & $\begin{array}{c}1.0(0.05) \\
{[0.90 \text { to } 1.09]}\end{array}$ & $0.02 *$ \\
\hline
\end{tabular}

Mean (SD), [range]. Running economy and energy cost was averaged over the three running speeds (6.0., 7.0, 8.0 mph for men, and 5.5, 6.5, 7.5 mph for women). *denotes statistical significance $(\mathrm{P}<0.05)$. While maximal heart rate, running economy, and energy cost were statistically significant between trials, the effect sizes were small and not meaningful. 
6.4 TABLE 4 Cardiopulmonary data for selected variables between groups

\begin{tabular}{|c|c|c|c|c|c|}
\hline & $\begin{array}{c}\text { Mean change (SD) } \\
{\left[\begin{array}{lll}95 \% & \mathrm{CI}\end{array}\right]}\end{array}$ & $\begin{array}{l}\text { Effect } \\
\text { size }\end{array}$ & SRM & $\begin{array}{c}\text { t- } \\
\text { statistic }\end{array}$ & $p$-value \\
\hline \multicolumn{6}{|c|}{ Stroke matched (control group) $(n=13,7$ men) } \\
\hline $\mathrm{VO}_{2 \max }(\mathrm{L} / \mathrm{min})$ & $\begin{array}{c}-0.1(0.2) \\
{[-0.2 \text { to } 0.1]}\end{array}$ & -0.07 & -0.34 & -0.98 & 0.35 \\
\hline $\mathrm{VO}_{2 \max }(\mathrm{mL} / \mathrm{kg} / \mathrm{min})$ & $\begin{array}{c}-1.2(3.1) \\
{[-3.2 \text { to } 0.9]}\end{array}$ & -0.24 & -0.37 & -1.23 & 0.25 \\
\hline $\begin{array}{l}\text { Running economy } \\
(\mathrm{mL} / \mathrm{kg} / \mathrm{km})\end{array}$ & $\begin{array}{l}-3.3(8.5) \\
{[-8.8 \text { to } 2.1]}\end{array}$ & -0.33 & -0.39 & -1.35 & 0.2 \\
\hline $\begin{array}{l}\text { Energy cost } \\
(\mathrm{kcal} / \mathrm{kg} / \mathrm{km})\end{array}$ & $\begin{array}{c}-0.02(.04) \\
{[-0.04 \text { to } 0.01]}\end{array}$ & -0.30 & -0.38 & -1.32 & 0.21 \\
\hline $\begin{array}{l}200 \text { yd. swimming } \\
\text { performance time ( } \mathrm{sec})\end{array}$ & $\begin{array}{l}+1.8(4.6) \\
{[-1.5 \text { to } 5.1]}\end{array}$ & 0.28 & 0.38 & 1.22 & 0.26 \\
\hline \multicolumn{6}{|c|}{ Controlled frequency breathing ( $n=12,7$ men) } \\
\hline $\mathrm{VO}_{2 \max }(\mathrm{L} / \mathrm{min})$ & $\begin{array}{c}+0.1(0.3) \\
{[-0.1 \text { to } 0.3]}\end{array}$ & 0.10 & 0.25 & 0.76 & 0.47 \\
\hline $\mathrm{VO}_{2 \max }(\mathrm{mL} / \mathrm{kg} / \mathrm{min})$ & $\begin{array}{l}+1.1(3.2) \\
{[-1.4 \text { to } 3.5]}\end{array}$ & 0.25 & 0.19 & 0.56 & 0.59 \\
\hline $\begin{array}{l}\text { Running economy } \\
(\mathrm{mL} / \mathrm{kg} / \mathrm{km})\end{array}$ & $\begin{array}{l}+1.8(9.5) \\
{[-5.5 \text { to } 9]}\end{array}$ & 0.17 & 0.19 & .056 & 0.59 \\
\hline $\begin{array}{l}\text { Energy cost } \\
(\mathrm{kcal} / \mathrm{kg} / \mathrm{km})\end{array}$ & $\begin{array}{c}+0.01(.05) \\
{[-0.03 \text { to } 0.05]}\end{array}$ & 0.16 & 0.19 & 0.58 & 0.58 \\
\hline $\begin{array}{l}200 \mathrm{yd} \text {. swimming } \\
\text { performance time }(\mathrm{sec})\end{array}$ & $\begin{array}{c}-0.1(1.5) \\
{[-1.2 \text { to } 1.1]}\end{array}$ & -0.01 & -0.05 & -0.16 & 0.88 \\
\hline
\end{tabular}

Mean (SD), [95\% CI]. The mean change is post-test minus pre-test values. CI, confidence interval; SRM, standardized response mean. 
TABLE 5 Reproducibility in cardiopulmonary variables from the graded exercise test

\begin{tabular}{|lcccc|}
\hline & $\begin{array}{c}\text { Day-to-Day } \\
\text { Variation (\%) }\end{array}$ & $\begin{array}{c}\text { Measurement } \\
\text { Error }\end{array}$ & Reproducibility & $\begin{array}{c}\text { Smallest } \\
\text { meaningful } \\
\text { change }\end{array}$ \\
\hline $\mathrm{VO}_{2 \max }(\mathrm{L} / \mathrm{min})$ & $3.4 \%$ & 0.14 & 0.39 & 0.20 \\
$\mathrm{VO}_{2 \max }$ & & & & \\
$(\mathrm{mL} / \mathrm{kg} / \mathrm{min})$ & $3.2 \%$ & 1.8 & 4.7 & 2.3 \\
$\mathrm{~V}_{\text {Emax }}(\mathrm{L} / \mathrm{min})$ & $4.6 \%$ & 5.3 & 14.6 & 7.3 \\
$\mathrm{RER}_{\max }$ & $3.0 \%$ & 0.03 & 0.09 & .04 \\
$\mathrm{HR}_{\max }$ & $2.1 \%$ & 3 & & 5 \\
$\begin{array}{l}\text { Oxygen pulse at } \\
\text { max mL/beat }\end{array}$ & $7.0 \%$ & 1.6 & 4.3 & 2.2 \\
$\begin{array}{l}\mathrm{Running} \text { economy } \\
(\mathrm{mL} / \mathrm{kg} / \mathrm{km})\end{array}$ & $2.4 \%$ & 4.3 & 11.8 & 5.9 \\
$\begin{array}{l}\text { Energy cost } \\
(\mathrm{kcal} / \mathrm{kg} / \mathrm{km})\end{array}$ & $2.5 \%$ & 0.03 & 0.09 & 0.04 \\
\hline
\end{tabular}

Data were pooled from both groups, $\mathrm{n}=25$. The results from familiarization trial and baseline trial. Some values were rounded to the nearest whole number. 


\title{
CURRICULUM VITAE
}

\author{
Patrick A. Sims
}

\section{Home Address:}

111 N Hite Ave

Apt. 5

Louisville, KY 40206

(502) 315-9045

\section{Personal Data:}

Birth Date: July 13, 1988

Birth Place: Atlanta, GA

Marital Status: Single

\section{Education:}

2002-2006

2006-2011

2013-Present
North Oldham High School, Goshen, KY

University of Kentucky, B.S. (Kinesiology)

University of Louisville, Masters Candidate

(Exercise Physiology)

\section{Community Service:}

Southern Arizona AIDS Foundation

AIDS Volunteers, Incorporated

\section{Honors and Awards:}

2006

2006-2007

2009-2010

2011

2013

2014
Cum Laude graduate, High School

Dean's List

University of Kentucky Group Fitness Instructor of the Year University of Kentucky Dept. of Campus Recreation Merit Award University of Arizona Mel \& Enid Zuckerman College of Public Health "Outstanding Community Health Representative" Scholarship Recipient University of Louisville Outstanding Masters of Science Exercise Physiology Student Award for Fall 2014 Commencement Recipient 
Presentations:

2008-2010

$2012-2013$

2014

2014
Midwest FitnessFest Fitness Conference,

Presenter:

"Kinesiology of Yoga" workshop

"Biomechanics of Cycling \& Proper Bike Setup" workshop

"Around the World" group cycling workout

University of Arizona College of Public Health, Guest lecturer:

CPH 350: Principles of Health Education \& Health Promotion

CPH 387: Health Disparities

University of Arizona Center for English as a Second Language

Guest lecturer:

TEFL 100: Introduction to University Life

University of Arizona Department of Campus Recreation,

Wellness lecturer:

"Living Pain Free"

"Lose Weight for Good"

Orangetheory ${ }^{\circledR}$ Fitness, Presenting Lecturer:

"Weight Loss: The Science and the Struggle"

Humana Health Insurance, Guest Speaker:

"The Science of Weight Loss" 